\title{
Unusual Behaviour During the Route of a Japp-Klingemann Reaction
}

\author{
Jan Marten $^{\mathrm{a}}$, Wilhelm Seichter ${ }^{\mathrm{a}}$, Jörg Wagler ${ }^{\mathrm{b}}$, and Edwin Weber ${ }^{\mathrm{a}}$ \\ ${ }^{a}$ Institut für Organische Chemie, TU Bergakademie Freiberg, Leipziger Straße 29, 09596 Freiberg/ \\ Sachsen, Germany \\ b Institut für Anorganische Chemie, TU Bergakademie Freiberg, Leipziger Straße 29, 09596 Freiberg/ \\ Sachsen, Germany
}

Reprint requests to Prof. Dr. Edwin Weber. Fax: +49 3731393170.

E-mail: edwin.weber@chemie.tu-freiberg.de

\section{Z. Naturforsch. 2010, 65b, 745 - 752; received March 4, 2010}

\begin{abstract}
Performing a standard Japp-Klingemann synthesis that involved diazotation of 2,6-dinitroaniline and reaction with pentane-2,4-dione in aqueous hydrochloric acid medium surprisingly yielded a mixture of the expected 2,6-dinitro- and the unexpected 2-chloro-6-nitro-substituted hydrazones. This mixture was isolated as solid-solution crystals containing the components in an approximate ratio of 1 to 2 . Based on both, selected compounds of comparison that show the aromatic ring substituents changed in position and intermediate diazonium salts, potential causal connections of the unusual behaviour during the route of the particular Japp-Klingemann reaction were studied. X-Ray crystal structures of the relevant compounds have been determined to support the discussion.
\end{abstract}

Key words: Pentane-2,4-dione, Anilines, Diazotation, Japp-Klingemann Reaction, X-Ray Diffraction Analysis

\section{Introduction}

The coupling reaction of a 1,3-dicarbonyl compound with an aromatic diazonium salt to yield a corresponding arylhydrazone is a well developed standard procedure, generally known as the Japp-Klingemann reaction [1]. It is mostly performed in acetate-buffered methanolic solution [2]. This method has given rise to an immense variety of arylhydrazones derived from various arylamines and 1,3-dicarbonyl compounds $[3,4]$. In this course, the respective aniline requires a preceeding diazotation with sodium nitrite in acidic medium to produce the corresponding diazonium salt [5], which is an inevitable part of the full synthetic route of a Japp-Klingemann mode of conversion.

Arylhydrazones obtained by the Japp-Klingemann reaction are in the focus of scientific interest due to their tautomerism behaviour [6], providing a promising tool for the design of functional materials attributed to smart (resonance-assisted) [7] hydrogen bonding [8]. Furthermore, their action as antineoplastic compounds [9] or chelate ligands for the complexation of transition metal ions is of scientific interest [10-13]. Hence, arylhydrazones of this type represent a rather important class of compounds with the Japp-Klingemann reaction being a significant and highly reliable approach for their synthesis $[2,12]$. This assumption has been fully supported lately [14-16], until our recent studies revealed an unusual and remarkable case when diazotised 2,6-dinitroaniline in aqueous hydrochloric acid plus pentane-2,4-dione were used for the reaction. The deviation from ordinary is shown in a partial replacement of one of the nitro groups by a chloro substituent at the aromatic ring. In our case, both the expected dinitrohydrazone $\mathbf{1}$ as well as the unexpected 2-chloro-6-nitro-substituted hydrazone 2 (Scheme 1) were obtained in an approximate ratio of 1 to 2 not only in solution but also in the form of a solid-solution as single crystals, thus asking for an explanation.

One may assume that the chloro substituent originates from the hydrochloric acid of the reaction medium, but at which step of the synthesis route the exchange could have taken place, either the diazonium salt or the hydrazone level, has remained uncertain. In order to clarify these facts, an extended study including the X-ray diffraction analysis of single crystals containing both compounds, $\mathbf{1}$ and $\mathbf{2}$, as a solid-solution, and the preparation and X-ray crystal structure determination of several appropriately constituted compounds of comparison (3-6) (Scheme 1) were carried out. The discussion also covers the known structure of compound $\mathbf{1}$, prepared by a modified procedure [15]. 
<smiles>CC(=O)C(=NNc1c([N+](=O)[O-])cccc1[N+](=O)[O-])C(C)=O</smiles>

1<smiles>O=[N+]([O-])c1cccc([N+](=O)[O-])c1[N+](=O)[O-]</smiles>

4<smiles>CC(=O)C(=NNc1c(Cl)cccc1[N+](=O)[O-])C(C)=O</smiles>

2<smiles></smiles>

5<smiles>CC(=O)C(=NNc1ccc([N+](=O)[O-])cc1[N+](=O)[O-])C(C)=O</smiles>

3<smiles>O=[N+]([O-])c1cccc([N+](=O)[O-])c1Cl</smiles>

6
Scheme 1. Compounds studied in this paper.

\section{Results and Discussion}

Japp-Klingemann reactions and preparation of reference compounds

As mentioned above, the reaction of diazotised 2,6dinitroaniline in aqueous $3 \mathrm{~N}$ hydrochloric acid with pentane-2,4-dione under standard Japp-Klingemann conditions led to the formation of a product which contains, according to ${ }^{1} \mathrm{H}$ NMR analysis, the expected dinitro hydrazone $\mathbf{1}$ and another unexpected 2,6 -disubstituted hydrazone in a ratio close to $1: 2$. The latter was then shown to be the chloro-nitro-substituted hydrazone 2 (vide infra). Without doubt, the chloro substituent is causally connected to the hydrochloric acid, but the way of replacement of the nitro group by a chlorine atom has remained unclear. Hence, on avoiding the chloride source by the use of sulphuric acid instead of hydrochloric acid in the reaction protocol, the mixed chloro nitro hydrazone should not appear. Indeed, in the absence of chloride, the reaction proceeded expectedly normal without substitution of a nitro group, producing the hydrazone $\mathbf{1}$ in high yield [15]. The different reaction outcomes from hydrochloric versus sulphuric acid medium suggest a nucleophilic attack of the chloride versus the sulphate or hydrogen sulphate ions, which is in agreement with the rather poor nucleophilic behaviour of the latter anions [17].

Prompted by the unexpected formation of single crystals containing both compounds, $\mathbf{1}$ and $\mathbf{2}$, as a solid-solution (vide infra), the question arose whether a similar nitro for chloro exchange will also occur during the course of a corresponding Japp-Klingemann reaction if a structurally modified dinitroaniline in hydrochloric acid medium, such as 2,4- instead of 2,6dinitroaniline, is used. The findings are that the constitutional isomeric dinitrohydrazone 3 (Scheme 1) is formed in nearly quantitative yield. According to these results, one can conclude that the position of the two nitro substituents at the aryl ring is the important parameter for the unusual reaction behaviour rather than their mere presence. This seems to be in agreement with earlier findings, showing that the efficient nucleophilic substitution of a nitro group requires a position of particular activation $[18,19]$ or the presence of an activating reaction medium [20], including a phase-transfer catalyst (Halex process) $[21,22]$. However, subsequent treatment of the 2,6dinitrophenylhydrazone $\mathbf{1}$ (alternatively prepared in sulphuric acid medium) with $3 \mathrm{~N}$ hydrochloric acid for $5 \mathrm{~h}$ at $50{ }^{\circ} \mathrm{C}$ did not lead to the chloro derivative 2 .

This tempted us to study the corresponding diazonium compounds, as the key intermediates of the reaction, since the reason for the unexpected replacement of nitro by chloro may be found at an earlier stage of the reaction. In order to obtain stable crystals for the structural study, the respective diazonium salts were isolated as the corresponding tetrafluoroborates $\mathbf{4}$ and 5 (Scheme 1). Although these compounds are sufficiently stable in the solid state, they vigorously decompose upon heating or in contact with various solvents 
and should be handled only in small quantities and with caution (see Experimental Section)! For a short-time storage, the covering with a layer of tetrafluoroboric acid is recommended.

In a final experiment, 2,6-dinitrobenzenediazonium tetrafluoroborate (4) was treated with $3 \mathrm{~N}$ aqueous hydrochloric acid, in order to probe its chemical behaviour under the conditions comparable to the initial Japp-Klingemann route. As a result of this treatment, a clear replacement of the diazonium group by a chlorine atom occurred, suggesting a nucleophilic substitution reaction with loss of gaseous nitrogen and the formation of tetrafluoroboric acid to yield 2,6-dinitrochlorobenzene (6) (Scheme 1). It seems obvious that this conversion follows an uncatalysed Sandmeyer-like dediazoniation reaction supported by the electron-withdrawing nitro groups [23, 24].

\section{$X$-Ray diffraction studies}

X-Ray diffraction analysis of the hydrazones and the diazonium salt intermediates were performed in order to obtain potentially helpful information about the uncommon course of the Japp-Klingemann reaction.

Upon crystallization of the reaction product, single crystals were obtained which contained $\mathbf{1}$ and $\mathbf{2}$ in the form of a solid-solution. Crystals are monoclinic, space group $P 2_{1} / n$ with $Z=4$. This means that $\mathbf{1}$ and $\mathbf{2}$ are statistically disordered in the crystal, the cor-

(a)

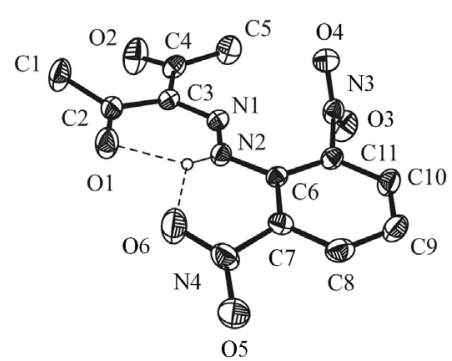

(b)

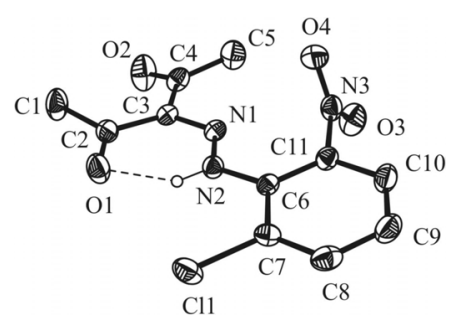

Fig. 1. Molecular structures of the hydrazones $\mathbf{1}$ (a) and 2 (b) in the solid-solution $\mathbf{1 / 2}$, including numbering schemes of the non-hydrogen atoms. Displacement ellipsoids are at the $50 \%$ probability level. Dashed lines represent hydrogen bonds. responding atoms of the two compounds sharing identical positions while only the nitro group $\mathrm{N}(4), \mathrm{O}(5)$, $\mathrm{O}(6)$ and the chlorine atom $\mathrm{Cl}(1)$ occupy different ones (Fig. 1). The ratio of $\mathbf{1}$ to $\mathbf{2}$ in the crystal was found to be 0.31 to 0.69 by refinement, close to the experimental ratio of 1 to 2 in solution (vide supra).

Both molecules exhibit a high degree of coplanarity with respect to the hydrazone and phenyl moieties. This structural feature, being a general phenomenon in this class of compounds [14-16], is a known consequence of the formation of an intramolecular hydrogen bridge within the hydrazone subunit and $\pi$ conjugation with the aryl ring. In 1 (Fig. 1a), one of the nitro groups is involved in a contact to the $(\mathrm{C}=\mathrm{O}) \mathrm{O}$ $\mathrm{N}$ bridging hydrogen, giving rise to a three-centre hydrogen contact $[\mathrm{O}(1) \cdots \mathrm{H}(2) \cdots \mathrm{O}(6)]$. Resulting therefrom, this nitro group is nearly coplanar with the aryl ring. The other nitro group of compound $\mathbf{1}$ is noticeably out of plane with respect to the aryl unit due to the repulsive interference with the lone pair of electrons at $\mathrm{N}(1)$ [15]. Thus, it is worth mentioning that the nitro group at $\mathrm{C}(11)$ of compound $\mathbf{2}$ is also out of plane, whereas the chloro substituent is neighbouring the position of the cyclic hydrogen bridge $\mathrm{O}(1) \cdots \mathrm{H}-$ $\mathrm{N}(2)$ (Fig. 1b). A further point of interest arises from a structural comparison of compound $\mathbf{1}$ in the neat crystal [15] and in the solid-solution with $\mathbf{2}$. It is demonstrated that $\mathbf{1}$ in the two different environments shows rather conformable molecular geometries. This refers to the hydrogen-bridged ring system and also to the different conformational orientation of the two nitro groups.

The molecular packing in crystals of $\mathbf{1 / 2}$ features a layer structure. The layers are stabilised by intermolecular $\mathrm{C}-\mathrm{H} \cdots \mathrm{O}$ contacts $[25,26]$ involving the aromatic carbon atom $\mathrm{C}(10)$ and the oxygen atom $\mathrm{O}(5)$ of the hydrogen-bonded nitro group of a neighbouring molecule. The chlorine atom of compound $\mathbf{2}$ gives rise to a similar $\mathrm{C}-\mathrm{H} \cdots \mathrm{Cl}$ contact. Another intermolecular $\mathrm{C}-\mathrm{H}$... O contact referring to the dinitrophenylhydrazone is found between $\mathrm{H}(10)$ and $\mathrm{O}(1)$, which is also present in the molecule of 2 . The layers are stacked to yield $\pi \cdots \pi$ interactions $[27,28]$ between the arene rings as well as between the hydrogen-bonded hydrazone system and a neighbouring aromatic ring [15]. Although the solid-solution composed of $\mathbf{1}$ and $\mathbf{2}$ reveals interesting structural details, these data do not contribute much to an explanation of the unusual course of the Japp-Klingemann reaction in the case of 2,6dinitroaniline. 


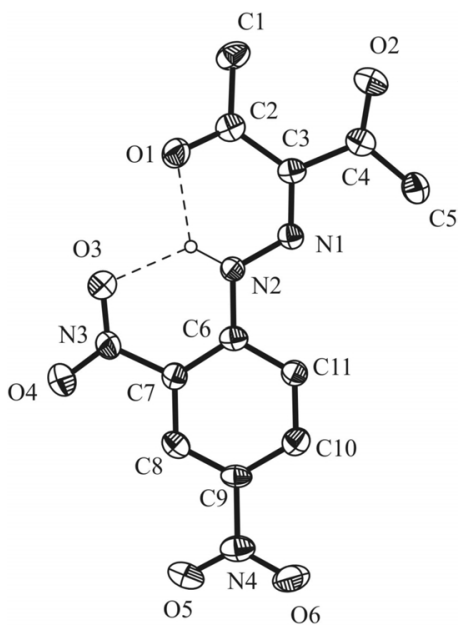

Fig. 2. Molecular structure of the hydrazone $\mathbf{3}$ with numbering scheme of the non-hydrogen atoms. Displacement ellipsoids are at the $50 \%$ probability level. Dashed lines represent hydrogen bonds.

Irrespective of the different substitution pattern at the phenyl group, the solid-state structure of the hydrazone 3 (Fig. 2) shows a high degree of correspondence to the constitutionally isomeric hydrazone $\mathbf{1}$ in the basic molecular geometry, including the bicyclic intramolecular hydrogen-bonded ring system. However, unlike 1, exhibiting the non-hydrogen-bonded ortho nitro group remarkably out of the aromatic ring plane, the para nitro group of $\mathbf{3}$ is nearly coplanar. Hence, also this nitro group shares the resonance with the arene unit, which is prevented in the case of $\mathbf{1}$ due to steric interference with the lone pair of electrons of $\mathrm{N}(1)$ [15]. As a result, the whole molecular geometry of $\mathbf{3}$ (non-hydrogen atoms) features a quasi plane. The crystalline packing mode of $\mathbf{3}$ can be described as composed of hydrogen-bonded molecular strands that are connected by weak $\mathrm{C}-\mathrm{H} \cdots \mathrm{O}$ contacts $[25,26]$.

In the crystal structure of 2,6-dinitrobenzenediazonium tetrafluoroborate (4), the nitro groups neighbouring the diazonium unit are rotated considerably out of the aryl ring plane (about 26 $6^{\circ}$. Hence, the $\mathrm{NO}_{2}$ moities detract from resonance, whereas the diazonium moiety is almost coplanar (Fig. 3a). The packing of 4 shows a rather complex arrangement of diazonium and tetrafluoroborate ions with B-F... N contacts [29]. Unlike 4, 2,4-dinitrobenzenediazonium tetrafluoroborate $(\mathbf{5})$ crystallises as a double salt $(1: 1)$ with sodium tetrafluoroborate as the second component. Due to the lower steric hindrance as compared with $\mathbf{4}$, both nitro groups of the diazonium cation (Fig. 3b) are no- (a)
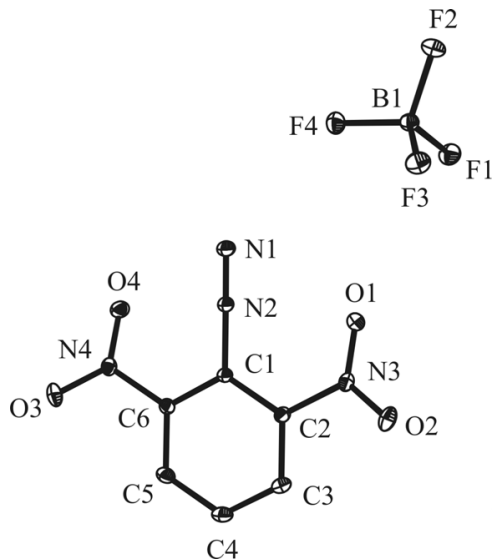

(b)

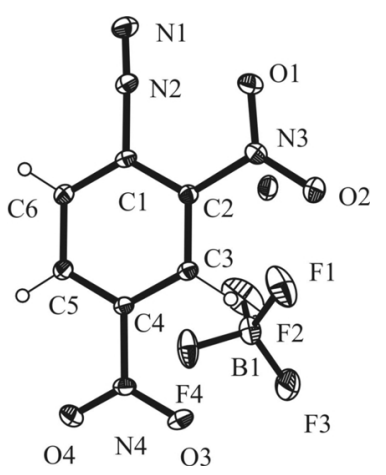

Fig. 3. Molecular structures of the diazonium salts 4 (a) and 5 (b), including numbering schemes of the non-hydrogen atoms. Displacement ellipsoids are at the $50 \%$ probability level.

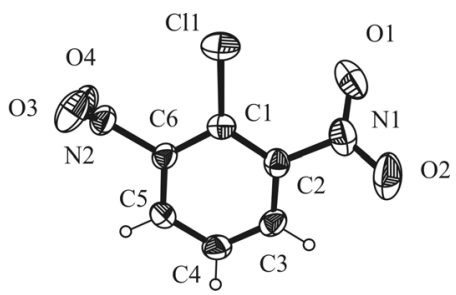

Fig. 4. Molecular structure of compound 6 with numbering scheme of the non-hydrogen atoms, showing the priority position of the disordered nitro groups. Displacement ellipsoids are at the $50 \%$ probability level.

tably less rotated out of the aryl plane (interplanar angles are 10 and $12^{\circ}$ ). An X-ray diffraction analysis was also performed of compound $\mathbf{6}$, revealing a molecular structure (Fig. 4) with the two nitro groups being conformationally disordered in two positions of different occupancies (85: 15 and $96: 4$ ).

Further details on the crystal structures are available (see notes at the end of the paper for availability). 


\section{Conclusions}

Although the well-known Japp-Klingemann synthesis [1], following the standard reaction protocol, usually produces the intended hydrazones [2-4], exceptions from this rule can occur. Such an exceptional case is met with the Japp-Klingemann reaction of diazotised 2,6-dinitroaniline with pentane-2,4-dione in aqueous hydrochloric acid, yielding aside from the expected 2,6-dinitrophenylhydrazone 1 also the 2-chloro6-nitro derivative 2 . These two compounds are capable of replacing each other in a crystal packing giving rise to a solid-solution crystal. Since neither the reaction using a mononitro-substituted arenediazonium salt $[14,15]$ nor that with the constitutionally isomeric $2,4-$ dinitrobenzenediazonium salt produced a corresponding chloro for nitro exchanged hydrazone but almost quantitative yields of the intended hydrazones, the conclusion is that both the number and the position of the nitro substituents are decisive factors. Moreover, because a subsequently performed vigorous treatment of the 2,6-dinitro-substituted hydrazone with $3 \mathrm{~N}$ hydrochloric acid did not indicate any transformation from 1 to 2 , it must be assumed that the reason for the exchange should be found at an earlier stage of the reaction before the hydrazone is formed, i.e. the step involving the diazonium salt. Supporting references in the literature [30-32] show aromatic nitro substituents to be good leaving groups (as nitrite) in the replacement by halogen and other nucleophiles, dependent on the temperature and the reaction time [30,33-35]. This is a potential line of reasoning to explain the result of the experiment in general. It is also known that aromatic nitro groups, being restrained due to the steric demand of neighbouring substituents and thus rotated out of the aromatic plane, are more easily replaced than nitro groups in conjugation with the aromatic system [36]. This observation is in agreement with the X-ray structural data of the diazonium salts, showing the 2,6and the 2,4-dinitro derivatives with considerably high and notably less rotation of the nitro groups out of the aryl plane, respectively. However, since we were unable to isolate a chloro for nitro-substituted by-product on reaction of the 2,6-dinitrobenzenediazonium cation with $3 \mathrm{~N}$ hydrochloric acid, the true path of the exchange reaction is not yet totally clear and requires further more detailed investigation. For example, one such investigation should analyse the potential presence of an arenediazotate which could add intramolecularly to the tilted nitro group and thus facilitate the nucleophilic substitution by chloride. Nevertheless it is an established fact that under particular circumstances reactions following a Japp-Klingemann route can take a course different from the normal case, such as shown here.

\section{Experimental Section}

NMR spectra (internal standard TMS) were recorded using a Bruker Avance DPX 400 instrument. IR spectroscopy was carried out on an FT-IR 510 Nicolet spectrometer. GCMS were determined with a Hewlett-Packard 5890 (Series II/MS 5989A) spectrometer. The elemental analyses were obtained using a Heraeus CHN rapid analyser. Organic solvents were purified by standard procedures [37]. Anilines, pentane-2,4-dione and tetrafluoroboric acid were purchased from Fluka.

\section{3-[(2,6-Dinitrophenyl)hydrazono]pentane-2,4-dione (1)}

A solution of the diazonium salt, prepared from 2,6-dinitroaniline $(3.66 \mathrm{~g}, 20.0 \mathrm{mmol})$ in conc. sulphuric acid $(20 \mathrm{~mL})$ and saturated sodium nitrite $(1.38 \mathrm{~g}, 20.0 \mathrm{mmol})$ in distilled water at $-5{ }^{\circ} \mathrm{C}$, was added to a stirred mixture of sodium acetate $(7.50 \mathrm{~g}, 91.5 \mathrm{mmol})$, sodium hydroxide (1.02 g, $25.0 \mathrm{mmol})$ and pentane-2,4-dione $(2 \mathrm{~mL}$, $1.90 \mathrm{~g}, 19.0 \mathrm{mmol})$ in methanol $(160 \mathrm{~mL})$ and distilled water $(160 \mathrm{~mL})$. Stirring was continued for $1 \mathrm{~h}$ at $\mathrm{r}$.t. The crude product was collected by filtration and crystallised from ethanol to yield $\mathbf{1}$ (4.83 g, $82 \%$ ) as yellow crystals, m. p. $153-155{ }^{\circ} \mathrm{C}$. Spectroscopic data correspond to the literature data [15].

3-[(2,6-Dinitrophenyl)hydrazono]pentane-2,4-dione (1) and 3-[(2-chloro-6-nitrophenyl)-hydrazono]pentane-2,4-dione (2)

The same procedure as above applies, except for the customary use of aqueous $3 \mathrm{~N}$ hydrochloric acid $(40 \mathrm{~mL})$ instead of sulphuric acid. Recrystallization from toluene yielded a solid-solution of $\mathbf{1}$ and $\mathbf{2}$ in a 32:68 ratio as yellow crystals (total yield $70 \%$ ), m.p. $178-180{ }^{\circ} \mathrm{C} .-{ }^{1} \mathrm{H}$ NMR $(400 \mathrm{MHz}$, $\left.\mathrm{CDCl}_{3}\right): \delta=2.34$ and $2.61\left(\mathrm{~m}, 12 \mathrm{H}, \mathrm{CH}_{3} \mathrm{CO}\right), 7.26(\mathrm{~d}, 1 \mathrm{H}$, Ar-H), 7.36 (d, $1 \mathrm{H}, \mathrm{Ar}-\mathrm{H}), 8.18(\mathrm{~d}, 2 \mathrm{H}, \mathrm{Ar}-\mathrm{H}), 8.36(\mathrm{~m}$, $2 \mathrm{H}, \mathrm{Ar}-\mathrm{H}), 15.17$ (s, $2 \mathrm{H}, \mathrm{NH}) \mathrm{ppm} .-{ }^{13} \mathrm{C} \mathrm{NMR}$ (100 MHz, $\left.\mathrm{CDCl}_{3}\right): \delta=26.3,31.7,123.0,124.9,130.1,131.9,137.6$, 140.5, 197.0, 198.7 ppm. - MS (GC-MS): $m / z=294$ (calcd. 294.06 for $\mathrm{C}_{11} \mathrm{H}_{10} \mathrm{~N}_{4} \mathrm{O}_{6},[\mathrm{M}]^{+}$), $m / z=284[\mathrm{M}+\mathrm{H}]^{+}$(calcd. 283.04 for $\mathrm{C}_{11} \mathrm{H}_{10} \mathrm{ClN}_{3} \mathrm{O}_{4}[\mathrm{M}]^{+}$).

\section{3-[(2,4-Dinitrophenyl)hydrazono]pentane-2,4-dione (3)}

The same procedure as above with hydrochloric acid instead of sulphuric acid applies. 2,4-Dinitroaniline was used 
Table 1. Crystal data and numbers pertinent to data collection and refinement of $\mathbf{1 / 2}-\mathbf{6}$.

\begin{tabular}{|c|c|c|c|c|c|}
\hline Compound & $1 / 2$ & 3 & 4 & 5 & 6 \\
\hline Empirical formula & $\mathrm{C}_{11} \mathrm{H}_{10} \mathrm{ClN}_{4} \mathrm{O}_{4}$ & $\mathrm{C}_{11} \mathrm{H}_{10} \mathrm{~N}_{4} \mathrm{O}_{6}$ & $\mathrm{C}_{6} \mathrm{H}_{3} \mathrm{BF}_{4} \mathrm{~N}_{4} \mathrm{O}_{4}$ & $\mathrm{C}_{6} \mathrm{H}_{3} \mathrm{~B}_{2} \mathrm{~F}_{8} \mathrm{NaN}_{4} \mathrm{O}_{4}$ & $\mathrm{C}_{6} \mathrm{H}_{3} \mathrm{ClN}_{2} \mathrm{O}_{4}$ \\
\hline Formula weight, $\mathrm{g} \mathrm{mol}^{-1}$ & 297.68 & 294.23 & 281.93 & 391.71 & 202.55 \\
\hline Crystal system & monoclinic & monoclinic & hexagonal & trigonal & monoclinic \\
\hline Space group & $P 2_{1} / n$ & $P 2_{1} / n$ & $P 6_{3} / m$ & $R 3 c$ & $C 2 / c$ \\
\hline$a, \AA$ & $11.0580(3)$ & $4.8914(6)$ & $12.0112(2)$ & 20.0892(4) & $13.223(4)$ \\
\hline$b, \AA$ & $8.0282(2)$ & $17.676(3)$ & $12.0112(2)$ & $20.0892(4)$ & $9.565(2)$ \\
\hline$c, \AA$ & $14.0430(4)$ & $14.564(2)$ & $11.8193(5)$ & $13.9635(8)$ & $13.479(4)$ \\
\hline$\alpha, \operatorname{deg}$ & 90 & 90 & 90 & 90 & 90 \\
\hline$\beta, \operatorname{deg}$ & $102.493(2)$ & $94.364(6)$ & 90 & 90 & $109.945(9)$ \\
\hline$\gamma, \mathrm{deg}$ & 90 & 90 & 120 & 120 & 90 \\
\hline$V, \AA^{3}$ & $1217.16(6)$ & $1255.6(3)$ & $1476.71(7)$ & $4880.3(3)$ & $1602.6(8)$ \\
\hline$Z$ & 4 & 4 & 6 & 6 & 8 \\
\hline$D_{\mathrm{c}}, \mathrm{Mg} \mathrm{m}^{-3}$ & 1.62 & 1.56 & 1.90 & 1.95 & 1.68 \\
\hline Temperature, $\mathrm{K}$ & $200(2)$ & $153(2)$ & $90(2)$ & $93(2)$ & $296(2)$ \\
\hline Measured reflections / $\theta_{\max }, \mathrm{deg}$ & $40860 / 33.5$ & $13425 / 22.0$ & $64535 / 45.0$ & $34374 / 35.0$ & $7934 / 29.0$ \\
\hline Completeness, $\%$ & 100.0 & 99.8 & 99.9 & 99.8 & 99.8 \\
\hline Unique reflections / $R_{\mathrm{int}}$ & $4775 / 0.0284$ & $1541 / 0.0539$ & $4201 / 0.0265$ & $2387 / 0.0267$ & $2125 / 0.0203$ \\
\hline Refined parameters & 198 & 196 & 103 & 205 & 130 \\
\hline Reflections $[I \geq 2 \sigma(I)]$ & 3849 & 1155 & 3706 & 2291 & 1527 \\
\hline$R 1 / w R 2[I \geq 2 \sigma(I)]$ & $0.0384 / 0.1104$ & $0.0367 / 0.0939$ & $0.0307 / 0.0912$ & $0.0326 / 0.0848$ & $0.0442 / 0.1231$ \\
\hline$R 1 / w R 2$ (all data) & $0.0505 / 0.1173$ & $0.0582 / 0.1183$ & $0.0367 / 0.0963$ & $0.0344 / 0.0865$ & $0.0631 / 0.1314$ \\
\hline$\Delta \rho_{\max / \min }$, e $\AA^{-3}$ & $0.410 /-0.186$ & $0.188 /-0.220$ & $0.839 /-0.736$ & $0.531 /-0.346$ & $0.199 /-0.280$ \\
\hline
\end{tabular}

instead of 2,6-dinitroaniline. Recrystallization from ethanol yielded $3(5.80 \mathrm{~g}, 98 \%)$ as yellow crystals, m. p. $208-210{ }^{\circ} \mathrm{C}$ (lit. [38]: $\left.211^{\circ} \mathrm{C}\right) .-{ }^{1} \mathrm{H}$ NMR $\left(400 \mathrm{MHz}, \mathrm{CDCl}_{3}\right): \delta=2.63$ and $2.71\left(\mathrm{~s}, 6 \mathrm{H}, \mathrm{CH}_{3} \mathrm{CO}\right), 8.28\left(\mathrm{~d},{ }^{3} \mathrm{~J}=9.6 \mathrm{~Hz}, 1 \mathrm{H}, \mathrm{Ar}-\mathrm{H}\right)$, $8.53\left(\mathrm{~d},{ }^{3} J=9.6 \mathrm{~Hz}, 1 \mathrm{H}, \mathrm{Ar}-\mathrm{H}\right), 9.22(\mathrm{~s}, 1 \mathrm{H}, \mathrm{Ar}-\mathrm{H}), 15.43$ (s, $1 \mathrm{H}, \mathrm{NH}) \mathrm{ppm} .-{ }^{13} \mathrm{C} \mathrm{NMR}\left(100 \mathrm{MHz}, \mathrm{CDCl}_{3}\right): \delta=26.8$, 31.8, 117.9, 122.9, 129.9, 134.1, 138.5, 142.7, 142.9, 196.6, 197.6 ppm. - IR (KBr): $v=3291,1685,1653,1612,1492$, $1358-1342,743 \mathrm{~cm}^{-1}$. - MS (GC-MS): $m / z=294$ (calcd. 294.06 for $\mathrm{C}_{11} \mathrm{H}_{10} \mathrm{~N}_{4} \mathrm{O}_{6}[\mathrm{M}]^{+}$). - Analysis $\mathrm{C}_{11} \mathrm{H}_{10} \mathrm{~N}_{4} \mathrm{O}_{6}$ (294.22): calcd. C 44.90, H 3.43, N 19.04; found C 44.95, H 3.41, N 19.04 .

Preparation of 2,6-dinitrobenzenediazonium tetrafluoroborate (4) and 2,4-dinitrobenzenediazonium tetrafluoroborate (5)

\section{General procedure}

To a stirred and cooled $\left(-5^{\circ} \mathrm{C}\right)$ suspension of the respective dinitroaniline $(3.66 \mathrm{~g}, 20.0 \mathrm{mmol})$ in tetrafluoroboric acid $(50 \mathrm{~mL}, 48 \%)$ was added dropwise during $20 \mathrm{~min}$ an ice-cooled solution of sodium nitrite $(1.38 \mathrm{~g}, 20.0 \mathrm{mmol})$ in distilled water $(10 \mathrm{~mL})$. The precipitate formed was collected and washed with tetrafluoroboric acid $(2 \times 5 \mathrm{~mL})$, ethanol $(2 \times 10 \mathrm{~mL})$ and diethyl ether $(2 \times 10 \mathrm{~mL})$, in this sequence. Data of the individual compounds are specified below.

4: Yield $5.20 \mathrm{~g}(92 \%)$ of a yellow solid which decomposes under violent explosion when heated above $200{ }^{\circ} \mathrm{C}$. Decomposition does also occur in contact with $\mathrm{CDCl}_{3}$, $\mathrm{D}_{3} \mathrm{COD},\left[\mathrm{D}_{8}\right]$ toluene, $\left[\mathrm{D}_{6}\right]$ benzene, $\left[\mathrm{D}_{6}\right] \mathrm{DMSO}$ and $\mathrm{D}_{2} \mathrm{O}$ preventing an NMR analysis. Warning! Cautious handling of this compound in small quantities is strongly advised!

5: Yield $4.90 \mathrm{~g} \mathrm{(81 \% )}$ of a yellow solid (dec. $>200{ }^{\circ} \mathrm{C}$ ). Warning! Decomposition hazards and precautionary advice as before!

\section{2,6-Dinitrochlorobenzene (6)}

To 2,6-dinitrobenzenediazonium tetrafluoroborate (4) $(1.00 \mathrm{~g}, 5.10 \mathrm{mmol})$ was added $3 \mathrm{~N}$ aqueous hydrochloric acid $(10 \mathrm{~mL})$ under vigorous stirring at $-5{ }^{\circ} \mathrm{C}$. The mixture was allowed to warm up to r.t., slowly heated to $50{ }^{\circ} \mathrm{C}$ and stirred for $1 \mathrm{~h}$ at this temperature. The precipitate was collected, washed twice with water $(100 \mathrm{~mL})$ and crystallised from ethanol to yield $6(0.49 \mathrm{~g}, 47 \%)$ as a colourless solid, m.p. $87-88{ }^{\circ} \mathrm{C}$ (dec.) [39]. $-{ }^{1} \mathrm{H}$ NMR data correspond to the lit. data [40]. $-{ }^{13} \mathrm{C} \mathrm{NMR} \mathrm{(100} \mathrm{MHz,} \mathrm{[D} 6$ DMSO): $\delta=$ 121.0, 130.1, 131.5, $148.9 \mathrm{ppm}$.

\section{$X$-Ray structure determinations}

Single crystals of compounds $1 / 2,3$ and $\mathbf{6}$ suitable for $\mathrm{X}$-ray diffraction studies were obtained by slow evaporation of solutions in ethanol. Crystals of compounds $\mathbf{4}$ and $\mathbf{5}$ were obtained from the cooled mother liquor of the reactions after $3 \mathrm{~d}$ storage at $4{ }^{\circ} \mathrm{C}$.

The reflection data were collected on a Bruker X8 APEX II diffractometer with graphite-monochromatised $\mathrm{Mo} K_{\alpha}$ radiation $(\lambda=0.71073 \AA)$ using $\omega$ and $\varphi$ scans. Reflections were corrected for background, Lorentz and polarisation effects. Preliminary structure models were derived by applica- 
tion of Direct Methods [41] and were refined by full-matrix least-squares calculations based on $F^{2}$ for all reflections [42]. All C-bound hydrogen atoms were included in the model in idealised positions (riding model), $\mathrm{N}$-bound hydrogen atoms were found by analysis of the residual electron density and refined without bond length restraints.

In $\mathbf{1} / \mathbf{2}$ also the nitro group $\mathrm{N}(4), \mathrm{O}(5), \mathrm{O}(6)$ and the chlorine atom $\mathrm{Cl}(1)$ could be refined with anisotropic displacement parameters, but EADP constraints [42] were applied to $\mathrm{N}(4)$ and $\mathrm{Cl}(1)$ while the sum of their respective refined occupancies was constrained to be 1.0.

The crystal data and experimental parameters are summarised in Table 1.
Supplementary information

CCDC 722411 (1/2), 722412 (3), 722413 (4), 722414 (5), and 722415 (6) contain the supplementary crystallographic data for this paper. These data can be obtained free of charge from The Cambridge Crystallographic Data Centre via www.ccdc.cam.ac.uk/data_request/cif.

Further details on the crystal structures, including tables of structure parameters and geometric parameters for non-covalent contacts as well as illustrations of the crystal packings are available as Supplementary Information (online only): www.znaturforsch.com/ab/v65b/c65b.htm.
[1] F. R. Japp, F. Klingemann, Liebigs Ann. Chem. 1888, $247,190-225$.

[2] R. R. Phillips, Org. React. 1959, 10, $143-178$.

[3] V. Bertolasi, V. Ferretti, P. Gilli, G. Gilli, J. Chem. Soc., Perkin Trans. 2 1993, 2223-2228.

[4] V. Bertolasi, L. Nanni, P. Gilli, V. Ferretti, G. Gilli, New. J. Chem. 1994, 18, 251-261.

[5] B. C. Challis, A. R. Butler, The Chemistry of the Amino Group, Wiley, New York, 1968.

[6] a) J. McVie, A. D. Mitchell, R. S. Sinclair, T. G. Truscott, J. Chem. Soc., Perkin Trans. 2 1980, 286-290; b) P. Courtot, R. Pichon, J. Le Saint, J. Chem. Soc, Perkin Trans. 2 1981, 219-221.

[7] G. Gilli, F. Bellucci, F. Ferretti, V. Bertolasi, J. Am. Chem. Soc. 1989, 111, $1023-1028$.

[8] P. Gilli, V. Bertolasi, V. Ferretti, G. Gilli, J. Am. Chem. Soc. 2000, 122, $10405-10417$.

[9] G. Garg, G. Sharma, J. Med. Chem. 1969, 12, $1122-$ 1124.

[10] N.P. Kuzmina, S. V. Eliseeva, A. M. Balashov, S. I. Trojanov, Z. Neorg. Chim. Moscow 2002, 47, $1300-$ 1304.

[11] B. A. El-Shetary, F. I. Zidan, Orient. J. Chem. 1987, 3, $120-122$.

[12] M. Dumic, D. Koruncev, K. Kovacevic, in Methoden Org. Chem., (Houben Weyl) Vol. E14b (Eds.: D. Klamann, H. Hagemann), Thieme, Stuttgart, 1988, p. 434.

[13] J. Albert, A. Gonzales, J. Granell, R. Moragas, C. Puerta, P. Valerla, Organometallics 1997, 16, 3775 3781.

[14] J. Marten, W. Seichter, E. Weber, Z. Anorg. Allg. Chem. 2005, 631, 869-877.

[15] J. Marten, W. Seichter, E. Weber, U. Böhme, J. Phys. Org. Chem. 2007, 20, 716-731.

[16] J. Marten, W. Seichter, E. Weber, U. Böhme, Cryst.Eng.Comm. 2008, 10, $541-547$.

[17] M. B. Smith, J. March, March's Advanced Organic Chemistry, $5^{\text {th }}$ ed., Wiley, New York 2001, pp. $438-$ 445.
[18] J. R. Beck, Tetrahedron 1978, 34, 2057-2068.

[19] G. I. Migachev, V. A. Danilenko, Chem. Heterocycl. Comp. 1982, 18, 649-762.

[20] N. Kornblum, L. Cheng, R. C. Kerber, M. M. Kestner, B. N. Newton, H. W. Pinnick, R. G. Smith, P. A. Wade, J. Org. Chem. 1976, 41, 1560-1564.

[21] C. Paradisi, U. Quintily, G. Scorrano, J. Org. Chem. 1983, 48, 3022-3026.

[22] W. C. Eckelman, Drug Discovery Today 2003, 8, $404-$ 410.

[23] P. R. Singh, R. Kumar, R. K. Khanna, Tetrahedron Lett. 1982, 23, $5191-5194$.

[24] L. I. Bagal, M. S. Pevzner, A. N. Frolov, J. Org. Chem. USSR 1969, 5, 1767.

[25] G. R. Desiraju, T. Steiner, The Weak Hydrogen Bond in Chemistry and Structural Biology, Oxford University Press, Oxford, 1999, pp. 29-121.

[26] M. Nishio in Encyclopedia of Supramolecular Chemistry, (Eds.: J. L. Atwood, J. W. Steed), Marcel Dekker, New York, 2004, p. 1576.

[27] S. L. James in Encyclopedia of Supramolecular Chemistry, (Eds.: J. L. Atwood, J. W. Steed), Marcel Dekker, New York, 2004, p. 1093.

[28] C. A. Hunter, Chem. Soc. Rev. 1994, $101-109$.

[29] K. Reichenbächer, H. I. Süss, J. Hulliger, Chem. Soc. Rev. 2005, 34, $22-30$.

[30] F. Effenberger, W. Streicher, Chem. Ber. 1991, 124, $157-162$.

[31] F. Effenberger, M. Koch, W. Streicher, Chem. Ber. 1991, 124, 163-173.

[32] M. B. Smith, J. March, March's Advanced Organic Chemistry, $5^{\text {th }}$ ed., Wiley, New York 2001, pp. $860-$ 861.

[33] G. C. Finger, C. W. Kruse, J. Am. Chem. Soc. 1956, 78, $6034-6037$.

[34] G. Bartoli, A. Latrofa, F. Naso, P. E. Todesco, J. Chem. Soc., Perkin Trans. 1 1972, 2671.

[35] G. Bartoli, P. E. Todesco, Acc. Chem. Res. 1977, 10, $125-132$. 
[36] F. Benedetti, D. R. Marshall, C. J. M. Stirling, J. L. Leng, J. Chem. Soc., Chem. Comm. 1982, $918-$ 919.

[37] J. Leonard, B. Lugo, G. Procter, Praxis der Organischen Chemie, VCH, Weinheim (Germany) 1994, pp. 53-68.

[38] P. Froeyen, P. Juvvik, Phosphorus, Sulfur, Silicon, Relat. Elem. 1992, 69, 83-91.

[39] L. H. Welsh, J. Am. Chem. Soc. 1941, 63, 3276-3278.

[40] R. Bacaloglu, A. Blasko, C. Bunton, E. Dorwin, F. Or- tega, C. Zucco, J. Am. Chem. Soc. 1990, 113, $238-$ 246.

[41] G. M. Sheldrick, SHELXS-97, Program for the Solution of Crystal Structures, University of Göttingen, Göttingen (Germany) 1997. See also: G. M. Sheldrick, Acta Crystallogr. 1990, A46, 467-473.

[42] G. M. Sheldrick, SHELXL-97, Program for the Refinement of Crystal Structures, University of Göttingen, Göttingen (Germany) 1997. See also: G. M. Sheldrick, Acta Crystallogr. 2008, A64, 112-122. 


\title{
Unusual Behaviour During the Route of a Japp-Klingemann Reaction
}

\author{
Jan Marten, ${ }^{a}$ Wilhelm Seichter, ${ }^{\mathrm{a}}$ Jörg Wagler, ${ }^{\mathrm{b}}$ and Edwin Weber ${ }^{\mathrm{a}}$
}

a Institut für Organische Chemie, TU Bergakademie Freiberg, Leipziger Straße 29, D-09596 Freiberg/Sachsen, Germany

b Institut für Anorganische Chemie, TU Bergakademie Freiberg, Leipziger Straße 29, D09596 Freiberg/Sachsen, Germany

\section{Supporting Information}

Table S1. Structure parameters of compounds $\mathbf{1}-\mathbf{3}$.

Table S2. Geometric parameters for non-covalent contacts in compounds 1-3.

Table S3. Structure parameters of compounds $\mathbf{4 - 6}$.

Table S4. Geometric parameters for intermolecular contacts in compounds 4-6.

Figure S1. Packing illustration for the solid solution 1/2 (arbitrary choice of $\mathbf{1}$ vs. 2). Heteroatoms are shaded; hydrogen bond type contacts are represented by dashed lines.

Figure S2. Packing structure of the hydrazone 3. Heteroatoms are shaded; hydrogen bond type contacts are represented by dashed lines.

Figure S3. Packing structure of the diazonium salt 4. Heteroatoms are shaded. Noncovalent interactions are represented by dashed lines. The shaded areas indicate the $\mathrm{N} \cdots \mathrm{F}$ contacts around a tetrafluoroborate anion. 
Figure S4. Packing excerpt of the double salt $\mathbf{5} \cdot \mathrm{NaBF}_{4}$. Heteroatoms are shaded (Na as a filled circle). Non-covalent interactions are represented by thin and dashed lines, except for $\mathrm{C}-\mathrm{H}$ bond. The tetrafluoroborate anions are illustrated with disordered positions.

Figure S5. Packing illustration of compound 6. Heteroatoms are shaded; non-covalent contacts are represented by dashed lines. 
Table S1. Structure parameters of compounds $\mathbf{1}-\mathbf{3}$.

\begin{tabular}{llll}
\hline Compound & $\mathbf{1}[15]$ & $\mathbf{1} / \mathbf{2}$ & $\mathbf{3}$ \\
\hline & & & \\
Bond lengths / $\AA$ & & & \\
& & & \\
$\mathrm{N}(1)-\mathrm{N}(2)$ & $1.333(2)$ & $1.325(1)$ & $1.337(3)$ \\
$\mathrm{N}(1)-\mathrm{C}(3)$ & $1.307(2)$ & $1.312(1)$ & $1.305(3)$ \\
$\mathrm{N}(2)-\mathrm{C}(6)$ & $1.386(2)$ & $1.387(1)$ & $1.385(3)$ \\
$\mathrm{C}(2)-\mathrm{C}(3)$ & $1.495(2)$ & $1.489(2)$ & $1.501(4)$ \\
$\mathrm{C}(3)-\mathrm{C}(4)$ & $1.498(2)$ & $1.495(2)$ & $1.493(4)$ \\
$\mathrm{C}(2)-\mathrm{O}(1)$ & $1.226(2)$ & $1.225(1)$ & $1.230(3)$ \\
$\mathrm{C}(4)-\mathrm{O}(2)$ & $1.216(2)$ & $1.214(2)$ & $1.216(3)$
\end{tabular}

Bond angles $/^{\circ}$

$\begin{array}{llll}\mathrm{C}(3)-\mathrm{N}(1)-\mathrm{N}(2) & 120.0(1) & 119.8(1) & 120.4(2) \\ \mathrm{N}(1)-\mathrm{N}(2)-\mathrm{C}(6) & 118.8(1) & 121.1(1) & 118.7(2) \\ \mathrm{N}(1)-\mathrm{C}(3)-\mathrm{C}(2) & 124.9(1) & 123.8(1) & 124.0(2) \\ \mathrm{N}(1)-\mathrm{C}(3)-\mathrm{C}(4) & 114.0(1) & 113.7(1) & 113.7(2) \\ \mathrm{C}(2)-\mathrm{C}(3)-\mathrm{C}(4) & 121.2(1) & 122.5(1) & 122.2(2) \\ \mathrm{C}(3)-\mathrm{C}(2)-\mathrm{O}(1) & 119.2(2) & 119.1(1) & 118.5(2) \\ \mathrm{C}(3)-\mathrm{C}(4)-\mathrm{O}(2) & 119.7(2) & 121.0(1) & 120.1(2)\end{array}$

Torsion angles $/^{\circ}$

$\begin{array}{llll}\mathrm{O}(1)-\mathrm{C}(2)-\mathrm{C}(3)-\mathrm{N}(1) & 14.1(3) & 8.2(2) & 12.4(4) \\ \mathrm{C}(2)-\mathrm{C}(3)-\mathrm{N}(1)-\mathrm{N}(2) & -6.0(3) & 2.2(2) & 0.2(4) \\ \mathrm{C}(3)-\mathrm{N}(1)-\mathrm{N}(2)-\mathrm{C}(6) & 177.3(2) & -176.3(1) & -178.2(2) \\ \mathrm{C}(2)-\mathrm{C}(3)-\mathrm{C}(4)-\mathrm{O}(2) & 26.6(3) & -15.9(2) & -12.6(4)\end{array}$

Interplanar angles $/^{\circ}$

$\begin{array}{llll}\operatorname{pla}(1)^{[\mathrm{a}]} \cdots \operatorname{pla}(2)^{[\mathrm{b}]} & 17.72(18) & 8.44 & 9.61 \\ \operatorname{pla}(1)^{[\mathrm{a}]} \cdots \operatorname{pla}(3)^{[\mathrm{c}]} & 67.04(8) & - & - \\ \operatorname{pla}(1)^{[\mathrm{a}]} \cdots \operatorname{pla}(4)^{[\mathrm{d}]} & 8.70(9) & - & -\end{array}$

Least-squares plane through ${ }^{[a]} \mathrm{C}(6)-\mathrm{C}(7)-\mathrm{C}(8)-\mathrm{C}(9)-\mathrm{C}(10)-\mathrm{C}(11),{ }^{[\mathrm{b}]} \mathrm{H}(2)-\mathrm{N}(2)-\mathrm{N}(1)-\mathrm{C}(3)-\mathrm{C}(2)-\mathrm{O}(1)$,

${ }^{[c]} \mathrm{N}(3)-\mathrm{O}(3)-\mathrm{O}(4),{ }^{[\mathrm{d}]} \mathrm{N}(4)-\mathrm{O}(5)-\mathrm{O}(6)$. 
Table S2. Geometric parameters for non-covalent contacts in compounds 1-3.

\begin{tabular}{|c|c|c|c|c|c|}
\hline \multirow{2}{*}{ Interaction } & \multirow[t]{2}{*}{ Symmetry } & \multicolumn{3}{|c|}{ Bond length / Å } & \multirow{2}{*}{$\frac{\text { Angle / }{ }^{\circ}}{\mathrm{D}-\mathrm{H} \cdots \mathrm{A}}$} \\
\hline & & $\mathrm{D}-\mathrm{H}$ & $\mathrm{D} \cdots \mathrm{H}$ & $\mathrm{H} \cdots \mathrm{A}$ & \\
\hline \multicolumn{6}{|l|}{$\mathbf{1}[15]$} \\
\hline $\mathrm{N}(2)-\mathrm{H}(2) \cdots \mathrm{O}(1)$ & $x, y, z$ & 0.79 & $2.597(2)$ & 2.01 & 130.9 \\
\hline $\mathrm{N}(2)-\mathrm{H}(2) \cdots \mathrm{O}(5)$ & $x, y, z$ & 0.79 & $2.605(2)$ & 2.01 & 130.4 \\
\hline $\mathrm{C}(1)-\mathrm{H}(1 \mathrm{~B}) \cdots \mathrm{O}(2)$ & $x, 1-y, 0.5+z$ & 0.98 & $3.411(2)$ & 2.57 & 143.2 \\
\hline $\mathrm{C}(1)-\mathrm{H}(1 \mathrm{~A}) \cdots \mathrm{O}(4)$ & $1+x, y, z$ & 0.98 & $3.123(2)$ & 2.64 & 139.3 \\
\hline $\mathrm{C}(5)-\mathrm{H}(5 \mathrm{~A}) \cdots \mathrm{O}(3)$ & $x, 1-y,-0.5+z$ & 0.98 & $3.578(2)$ & 2.63 & 163.1 \\
\hline $\mathrm{C}(1)-\mathrm{H}(1 \mathrm{~A}) \cdots \mathrm{O}(6)$ & $0.5+x, 0.5-y, 0.5+z$ & 0.98 & $3.323(2)$ & 2.53 & 138.2 \\
\hline $\mathrm{C}(5)-\mathrm{H}(5 \mathrm{C}) \cdots \mathrm{O}(6)$ & $-0.5+x, 0.5-y,-0.5+z$ & 0.98 & $3.423(2)$ & 2.46 & 167.6 \\
\hline \multicolumn{6}{|l|}{$1 / 2$} \\
\hline $\mathrm{N}(2)-\mathrm{H}(2) \cdots \mathrm{O}(1)$ & $x, y, z$ & 0.86 & 2.539 & 1.84 & 135.9 \\
\hline $\mathrm{N}(2)-\mathrm{H}(2) \cdots \mathrm{O}(5)$ & $x, y, z$ & 0.86 & 2.606 & 1.99 & 127.3 \\
\hline $\mathrm{C}(10)-\mathrm{H}(10) \cdots \mathrm{O}(5)$ & $-2-x, 1-y,-z$ & 0.93 & 3.305 & 2.43 & 172.9 \\
\hline $\mathrm{C}(10)-\mathrm{H}(10) \cdots \mathrm{O}(1)$ & $-0.5+x, 1.5-y,-0.5+z$ & 0.93 & 3.387 & 2.61 & 106.8 \\
\hline $\mathrm{C}(9)-\mathrm{H}(9) \cdots \mathrm{O}(4)$ & $1.5-x, 0.5+y,-1.5-z$ & 0.93 & 3.316 & 2.65 & 113.7 \\
\hline $\mathrm{C}(10)-\mathrm{H}(10) \cdots \mathrm{Cl}(1)$ & $0.5+x, 0.5+y, 0.5+z$ & 0.93 & 3.825 & 3.10 & 150.0 \\
\hline \multicolumn{6}{|l|}{3} \\
\hline $\mathrm{N}(2)-\mathrm{H}(2) \cdots \mathrm{O}(1)$ & $x, y, z$ & 0.95 & 2.568 & 1.88 & 128 \\
\hline $\mathrm{N}(2)-\mathrm{H}(2) \cdots \mathrm{O}(3)$ & $x, y, z$ & 0.95 & 2.619 & 1.93 & 128 \\
\hline $\mathrm{C}(1)-\mathrm{H}(1 \mathrm{~A}) \cdots \mathrm{O}(6)$ & $2+x, 0.5-y, 0.5+z$ & 0.98 & 3.440 & 2.59 & 145 \\
\hline $\mathrm{C}(5)-\mathrm{H}(5 \mathrm{~A}) \cdots \mathrm{O}(2)$ & $-1+x, y, z$ & 0.98 & 3.396 & 2.48 & 155 \\
\hline $\mathrm{C}(10)-\mathrm{H}(10) \cdots \mathrm{O}(1)$ & $-1+x, 0.5-y,-0.5+z$ & 0.95 & 3.298 & 2.39 & 160 \\
\hline
\end{tabular}


Table S3. Structure parameters of compounds 4-6.

\begin{tabular}{|c|c|c|c|}
\hline Compound & 4 & 5 & 6 \\
\hline \multicolumn{4}{|l|}{ Bond lengths / $\AA$} \\
\hline $\mathrm{N}(1)-\mathrm{N}(2)$ & $1.098(1)$ & $1.093(2)$ & - \\
\hline $\mathrm{N}(2)-\mathrm{C}(1)$ & $1.394(1)$ & $1.409(2)$ & - \\
\hline $\mathrm{C}(2)-\mathrm{N}(3)$ & $1.464(1)$ & $1.461(2)$ & - \\
\hline $\mathrm{N}(3)-\mathrm{O}(1)$ & $1.220(1)$ & $1.228(2)$ & - \\
\hline $\mathrm{N}(3)-\mathrm{O}(2)$ & $1.221(1)$ & $1.219(2)$ & - \\
\hline $\mathrm{C}(1)-\mathrm{C}(2)$ & $1.395(1)$ & $1.398(2)$ & - \\
\hline $\mathrm{B}(1)-\mathrm{F}(1-4)$ & $1.372(2)-1.422(2)$ & $1.362(3)-1.406(3)$ & - \\
\hline $\mathrm{C}(2)-\mathrm{N}(1)$ & - & - & $1.476(2)$ \\
\hline $\mathrm{C}(6)-\mathrm{N}(2)$ & - & - & $1.469(2)$ \\
\hline $\mathrm{N}(1)-\mathrm{O}(1)$ & - & - & $1.229(2)$ \\
\hline $\mathrm{N}(2)-\mathrm{O}(3)$ & - & - & $1.215(3)$ \\
\hline $\mathrm{N}(1)-\mathrm{O}(2)$ & - & - & $1.193(2)$ \\
\hline $\mathrm{N}(2)-\mathrm{O}(4)$ & - & - & $1.223(3)$ \\
\hline \multicolumn{4}{|l|}{ Bond angles $/^{\circ}$} \\
\hline$N(1)-N(2)-C(1)$ & $178.9(1)$ & $175.4(2)$ & - \\
\hline $\mathrm{N}(2)-\mathrm{C}(1)-\mathrm{C}(2)$ & $119.9(1)$ & $120.5(1)$ & - \\
\hline $\mathrm{C}(1)-\mathrm{C}(2)-\mathrm{N}(3)$ & $120.7(1)$ & $122.0(1)$ & - \\
\hline $\mathrm{C}(2)-\mathrm{N}(3)-\mathrm{O}(1)$ & $117.2(1)$ & 116.8(1) & - \\
\hline $\mathrm{C}(2)-\mathrm{N}(3)-\mathrm{O}(2)$ & 117.0(1) & 117.5(1) & - \\
\hline \multicolumn{4}{|l|}{ Torsion angles $/^{\circ}$} \\
\hline $\mathrm{N}(2)-\mathrm{C}(1)-\mathrm{C}(2)-\mathrm{N}(3)$ & $-1.76(6)$ & $6.6(2)$ & - \\
\hline $\mathrm{C}(1)-\mathrm{C}(2)-\mathrm{N}(3)-\mathrm{O}(1)$ & $154.38(4)$ & $10.1(2)$ & - \\
\hline $\mathrm{C}(1)-\mathrm{C}(2)-\mathrm{N}(3)-\mathrm{O}(2)$ & $152.89(4)$ & $-170.4(1)$ & - \\
\hline $\mathrm{C}(3)-\mathrm{C}(2)-\mathrm{N}(3)-\mathrm{O}(1)$ & $-26.43(5)$ & $-168.1(1)$ & - \\
\hline
\end{tabular}


Table S4. Geometric parameters for intermolecular contacts in compounds 4-6.

\begin{tabular}{|c|c|c|c|c|c|}
\hline \multirow{2}{*}{ Interaction } & \multirow[t]{2}{*}{ Symmetry } & \multicolumn{3}{|l|}{ Bond length / Å } & \multirow{2}{*}{$\begin{array}{l}\text { Angle / }{ }^{\circ} \\
\mathrm{C}-\mathrm{H} \cdots \mathrm{O}, \mathrm{F} /[\mathrm{B}-\mathrm{F} \cdots \mathrm{F}, \mathrm{N}]\end{array}$} \\
\hline & & $\mathrm{C}-\mathrm{H} /[\mathrm{B}-\mathrm{F}]$ & $\mathrm{H} \cdots \mathrm{O}, \mathrm{F} /[\mathrm{F} \cdots \mathrm{F}, \mathrm{N}]$ & $\mathrm{C}-\mathrm{O}, \mathrm{F} /[\mathrm{B} \cdots \mathrm{F}, \mathrm{N}]$ & \\
\hline \multicolumn{6}{|l|}{4} \\
\hline $\mathrm{C}(3)-\mathrm{H}(3) \cdots \mathrm{O}(1)$ & $1-x, 1-y,-0.5+z$ & 0.95 & 2.54 & 3.066 & 115 \\
\hline $\mathrm{C}(3)-\mathrm{H}(3) \cdots \mathrm{O}(2)$ & $1+x, y, 0.5-z$ & 0.95 & 2.94 & 3.247 & 100 \\
\hline $\mathrm{C}(3)-\mathrm{H}(3) \cdots \mathrm{F}(1)$ & $-x+y,-x, z$ & 0.95 & 2.57 & 3.494 & 164 \\
\hline $\mathrm{B}(1)-\mathrm{F}(1) \cdots \mathrm{F}(1)$ & $1-x+y, 1-x, z$ & $1.40[\mathrm{~B}(1)-\mathrm{F}(1)]$ & $4.013[\mathrm{~B}(1)-\mathrm{F}(1) \cdots \mathrm{F}(1)]$ & $3.329[\mathrm{~B}(1) \cdots \mathrm{F}(1)]$ & $109.2[\mathrm{~B}(1)-\mathrm{F}(1) \cdots \mathrm{F}(1)]$ \\
\hline$B(1)-F(1) \cdots N(1)$ & $x-y, x,-0.5+z$ & $1.40[\mathrm{~B}(1)-\mathrm{F}(1)]$ & $2.889[\mathrm{~B}(1)-\mathrm{F}(1) \cdots \mathrm{N}(1)]$ & $4.121[\mathrm{~B}(1) \cdots \mathrm{N}(2)]$ & $145.7[\mathrm{~B}(1)-\mathrm{F}(1) \cdots \mathrm{N}(1)]$ \\
\hline \multicolumn{6}{|l|}{5} \\
\hline $\mathrm{C}(3)-\mathrm{H}(3) \cdots \mathrm{O}(4)$ & $1 / 3-x+y, 2 / 3-x,-1 / 3+z$ & 0.95 & 2.46 & 3.400 & 173 \\
\hline $\mathrm{C}(5)-\mathrm{H}(5) \cdots \mathrm{F}(2)$ & $x, x-y, 0.5+z$ & 0.95 & 2.38 & 3.234 & 149 \\
\hline $\mathrm{C}(6)-\mathrm{H}(6) \cdots \mathrm{F}(1)$ & $-x+y, y, 0.5+z$ & 0.95 & 2.33 & 3.222 & 157 \\
\hline \multicolumn{6}{|l|}{6} \\
\hline $\mathrm{C}(4)-\mathrm{H}(4) \cdots \mathrm{O}(3)$ & $0.5-x, 0.5+y, 0.5-z$ & 0.93 & 2.59 & 3.361 & 141.0 \\
\hline $\mathrm{C}(5)-\mathrm{H}(5) \cdots \mathrm{O}(1)$ & $0.5+x, 1.5+y, 0.5+z$ & 0.93 & 2.55 & 3.313 & 147.7 \\
\hline
\end{tabular}



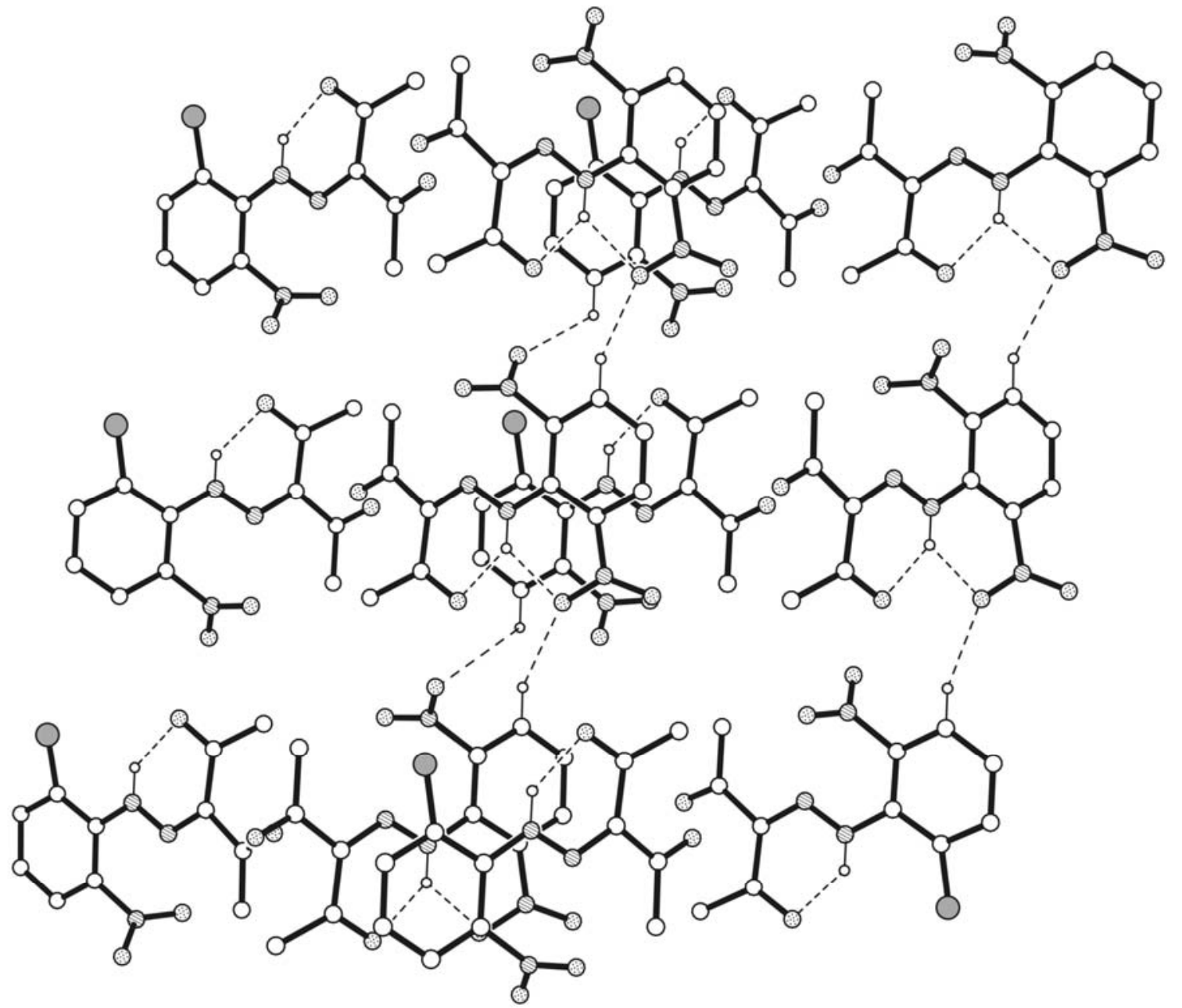

Figure S1. Packing illustration of the solid solution 1/2 (arbitrary choice of $\mathbf{1}$ vs. 2). Heteroatoms are shaded; hydrogen bond type contacts are represented by dashed lines. 


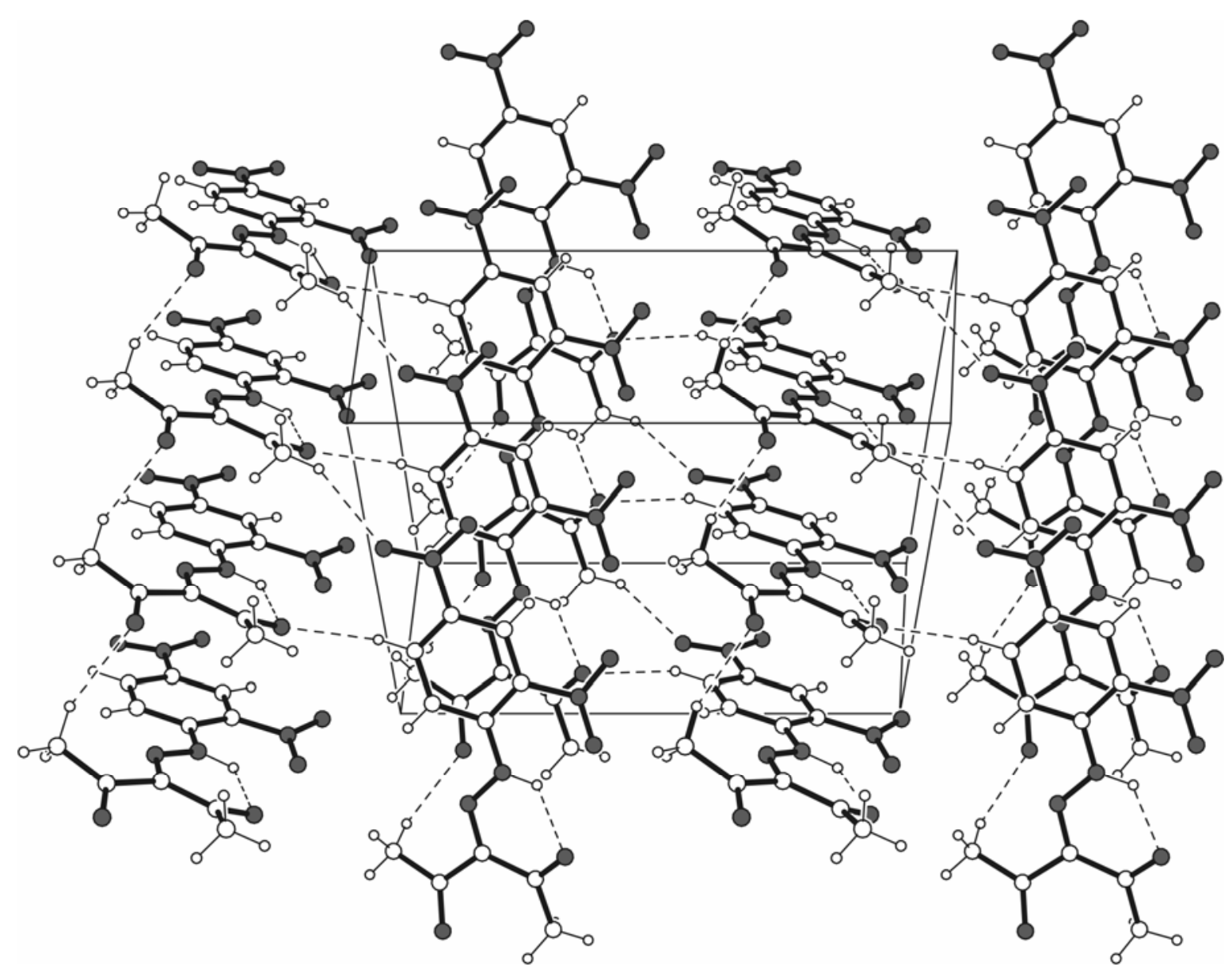

Figure S2. $\quad$ Packing structure of the hydrazone 3. Heteroatoms are shaded; hydrogen bond type contacts are represented by dashed lines. 


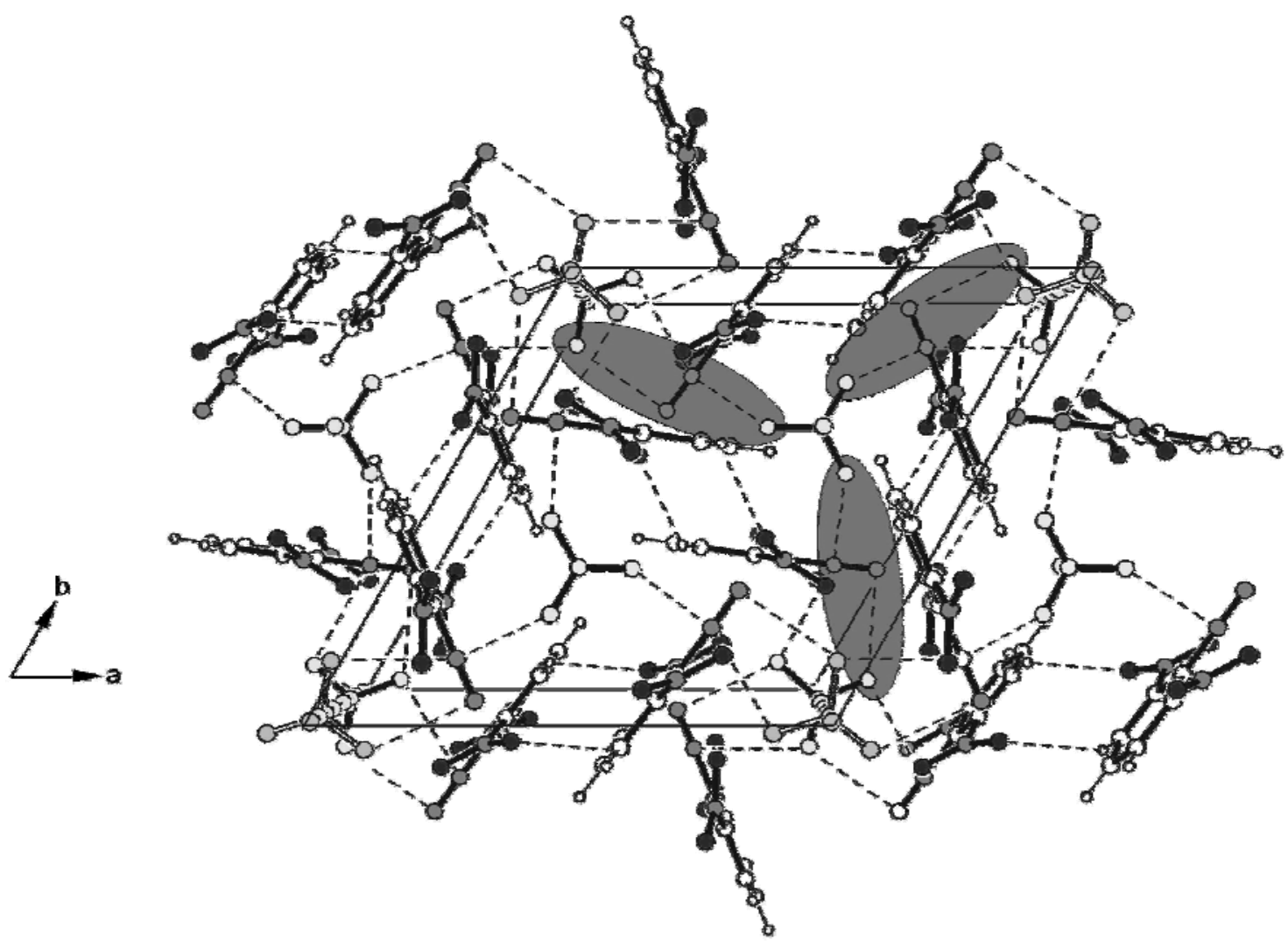

Figure S3. Packing structure of the diazonium salt 4. Heteroatoms are shaded. Noncovalent interactions are represented by dashed lines. The shaded areas indicate the $\mathrm{N} \cdots \mathrm{F}$ contacts around a tetrafluoroborate anion. 


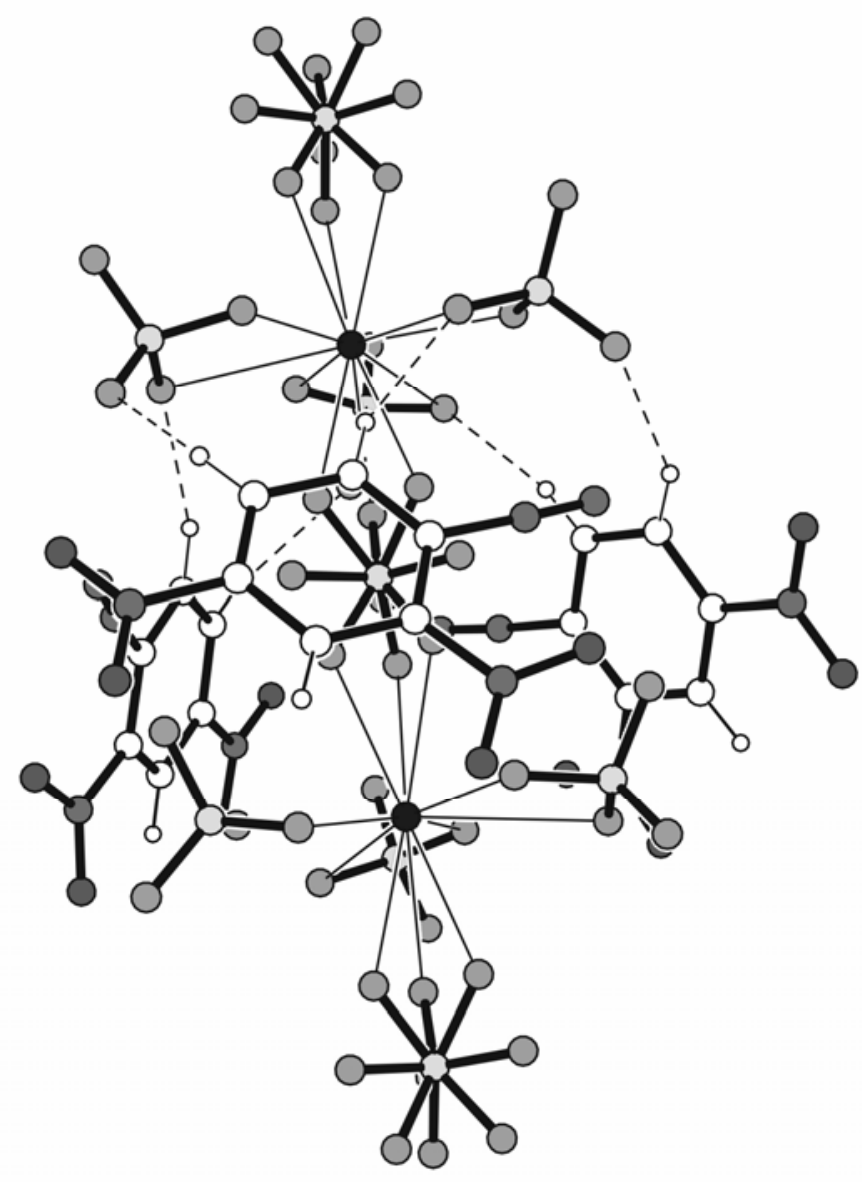

Figure S4. Packing exerpt of the double salt 5. $\mathrm{NaBF}_{4}$. Heteroatoms are shaded (Na as a filled circle). Non-covalent interactions are represented by thin and dashed lines, except for C-H bonds. The tetrafluoroborate anions are illustrated with disordered positons. 


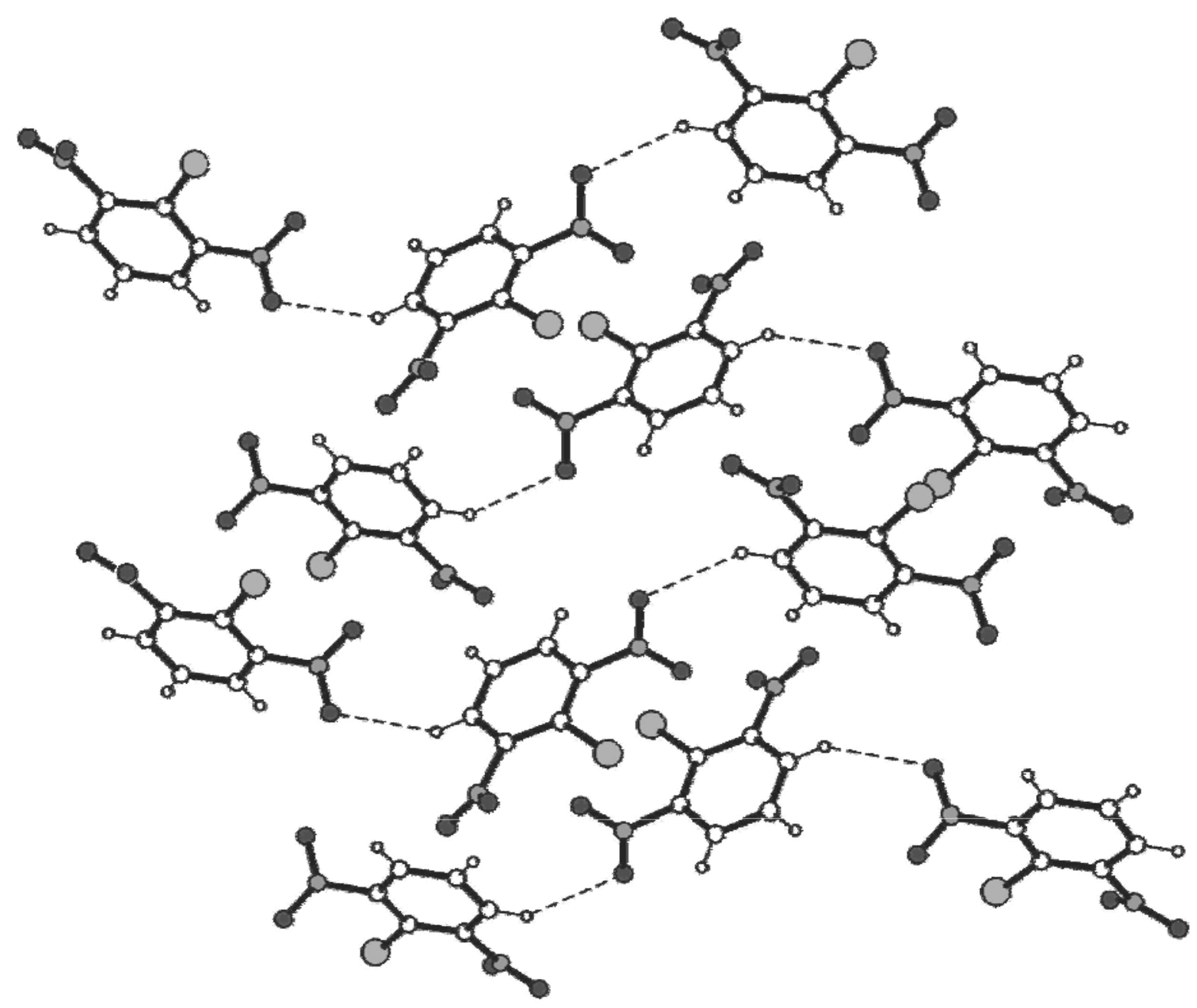

Figure S5. Paking illustration of compound 6. Heteroatoms are shaded; non-covalent contacts are represented by dashed lines. 